\title{
Ejpidemiological Study of Road Traffic Accidents and Detection of Accident Hot Spot in Golestan Province, Northern Iran
}

\author{
Hassan Khorshah ${ }^{1}$, Maryam Eri ${ }^{1}$, Mohammad Reza Honarvar ${ }^{* 2}$, Seyed Kamal Mirkarimi², Mahdi \\ Abbasi ${ }^{1}$, Farhad Badiei ${ }^{3}$, Masoumeh Gholami ${ }^{3}$, Mohammad Montazeri ${ }^{1}$ \\ 1. Health Management and Social Development Research Center, Golestan University of Medical \\ Sciences, Gorgan, Iran \\ 2. Health Management and Social Development Research Center, School of Public Health, Golestan \\ University of Medical Sciences, Gorgan, Iran \\ 3. Deputy of Health, Golestan University of Medical Sciences, Gorgan, Iran
}

\begin{abstract}
Background and objectives: Given the high burden of traffic accidents in Iran, especially in the northern areas, and the importance of identifying the characteristics and geographic distribution of road traffic accidents (RTAs) for policymaking and planning, this study was conducted to investigate the epidemiology of RTAs and determine accident hot spots in the Golestan Province, northern Iran.
\end{abstract}

Methods: This cross-sectional study was carried out on all traffic accidents in the suburban roads of the Golestan Province that were reported to the Emergency Medical Services (EMS 115) and registered in a software-based traffic accidents information management system (called SAMAH in Persian) between March 2009 and 2012. The accidents were assessed in terms of setting, time of accident, demographic characteristics of injured people, and consequences. Data were entered into SPSS (version 16) and then analyzed using independent t-test and chi-square test. The ArcGIS 10 software was also used for analyzing spatial data and mapping RTAs.

Results: Overall, 10522 incidents were recorded in the system, most of which (36.2\%) occurred in March 2010-2011. The frequency of RTAs in summer was almost 2-fold higher than other seasons. In addition, the frequency of RTAs was higher in the Gonbad-e-Kavous County $(23.4 \%)$ and the Gorgan County (21.4\%). Among the 11,415 people injured in RTAs, 9,129 (82.1\%) were male, $80.7 \%$ were transferred to hospital, and $5.9 \%$ were treated at the accident site. The mean age of injured men (29.9 \pm 14.9 years) was significantly lower than that of injured women $(33.2 \pm 17$ years) $(\mathrm{P} \leq 0.001)$. Moreover, 163 individuals $(1.4 \%)$ died because of the RTAs, and mission was canceled in 1393 cases $(12 \%)$. The most common RTA injuries were multiple traumas $(34.6 \%)$, head and face injuries (28.3\%), and knee and leg injuries (18.1\%).

Conclusion: We demonstrated that the rate of RTAs in the Golestan Province is high. Offering training to people, especially to younger people who at higher risk of involvement in RTAs, improving road quality and signage in hot spots, and recruitment of highly-trained EMS personnel might be beneficial for reducing the number and complications of RTAs in the province.

KEYWORDS: Geographic Information Systems, Traffic Accidents, Epidemiology, Iran

\section{Received: 2018/11/14 $\quad$ Revised:2018/12/01 $\quad$ Published:2019/01/11}

*Correspondence: Dr Mohammad Reza Honarvar

Address: Health Management and Social Development Research Center, $1^{\text {st }}$ Golbarg, Golha alley, Gorgan, Iran

Telephone: +98-1732160330 Email: honarvar@goums.ac.ir 


\section{INTRODUCTION}

Road traffic accidents (RTAs) are a major public health problem in many parts of the world. The rate of deaths caused by RTAs is higher in low- and middle-income countries (1). According to the Global Burden of Disease study in 2010, RTAs are the second leading cause of death and the main cause of disability adjusted life years lost in Iran (2). In Iran, RTA-associated mortality rate is approximately 30-44 death per 100,000 people, which is almost twice the rate in European countries (3-6).

In the north of Iran, the burden of traffic accidents is high $(7,8)$ and the rate of fatal accidents is higher than other parts of the country because of crowded roads (9). Thus, it is vital to investigate characteristics and the geographic distribution of RTAs based on the geographic information systems (GIS) in this area (10).

Although some studies investigated the epidemiology of RTAs in the Golestan Province, north of Iran, the majority of these studies had a small sample size (11) or were based on the data from the traffic police (12) or the forensic medicine organization (9), which might not be a good representative of the actual RTA data of the province. Moreover, these studies did not specify traffic accident hot spots to guide road managers and policymakers for the necessary interventions. Therefore, this study aimed to determine accident hot spots and the epidemiological characteristics of RTAs in the Golestan Province between 2009 and 2012 using a comprehensive software-based data system (SAMAH) and a GIS software.

\section{MATERIAL AND METHODS \\ Study population}

This cross-sectional study was carried out on all traffic accidents in the suburban roads of the Golestan Province that were reported to the Emergency Medical Services (EMS 115) between March 2009 and 2012.

\section{Study protocol}

Data were collected using standard forms, which were distributed across all pre-hospital emergency sites by the Provincial Emergency Operations Center. Pre-hospital emergency medical personnel who were dispatched to the accident sites completed the forms. The forms included demographic characteristics of the people injured (such as age, sex, and type of injury), place and time of the accident, and the result of dispatch (transfer to hospital, treatment at site, or death). All teams dispatched to the accident sites completed the relevant forms and returned them to the prehospital emergency sites. Trained pre-hospital emergency personnel entered the data into a software-based traffic accidents information management system (called SAMAH in Persian). In a separate research project supported by the Golestan University of Medical Sciences, experts in the field of GIS designed this system to increase data availability and efficient use of RTAs information collected from all organizations involved in RTAs in the province including the Red Crescent Society, EMS 115, and the Legal Medicine Organization.

\section{Statistical analysis}

Data were described using descriptive statistics including mean, standard deviation (SD), median, and mode. Statistical analysis of data was performed using SPSS software (version 16) and differences between demographic characteristics and injuries were assessed using independent t-test and chisquare test. The ArcGIS 10 software was also used for analyzing spatial data and mapping RTAs. P-values less than 0.05 were considered statistically significant.

\section{RESULTS}

\section{Location and characteristics of RTAs}

Based on the data from the EMS 115, 10522 RTAs and 11415 injuries (1.1 injury per accident) occurred between March 2009 and 2012. Most accidents (36.6\%) occurred in March 2010-2011 (Table 1). 
Table 1. Frequency of RTAs, injuries and deaths in the Golestan Province during 2009-2012, based on the data from the EMS 115

\begin{tabular}{|c|c|c|c|}
\hline Year & $\begin{array}{c}\text { Accidents } \\
\mathbf{N}(\boldsymbol{\%})\end{array}$ & $\begin{array}{c}\text { Injuries } \\
\mathbf{N}(\boldsymbol{\%})\end{array}$ & $\begin{array}{c}\text { Deaths } \\
\mathbf{N}(\boldsymbol{\%})\end{array}$ \\
\hline $\mathbf{2 0 0 9 - 2 0 1 0}$ & $3346(31.8)$ & $3620(31.7)$ & $59(36.2)$ \\
\hline $\mathbf{2 0 1 0 - 2 0 1 1}$ & $3850(36.6)$ & $4132(36.2)$ & $60(36.8)$ \\
\hline $\mathbf{2 0 1 1 - 2 0 1 2}$ & $3326(31.6)$ & $3663(32.1)$ & $44(27)$ \\
\hline Total & $10522(100)$ & $11415(100)$ & $163(100)$ \\
\hline
\end{tabular}

In addition, frequency of RTAs was higher in the Gonbad-e-Kavous County (23.4\%) and the Gorgan County (21.4\%) (Figure 1).

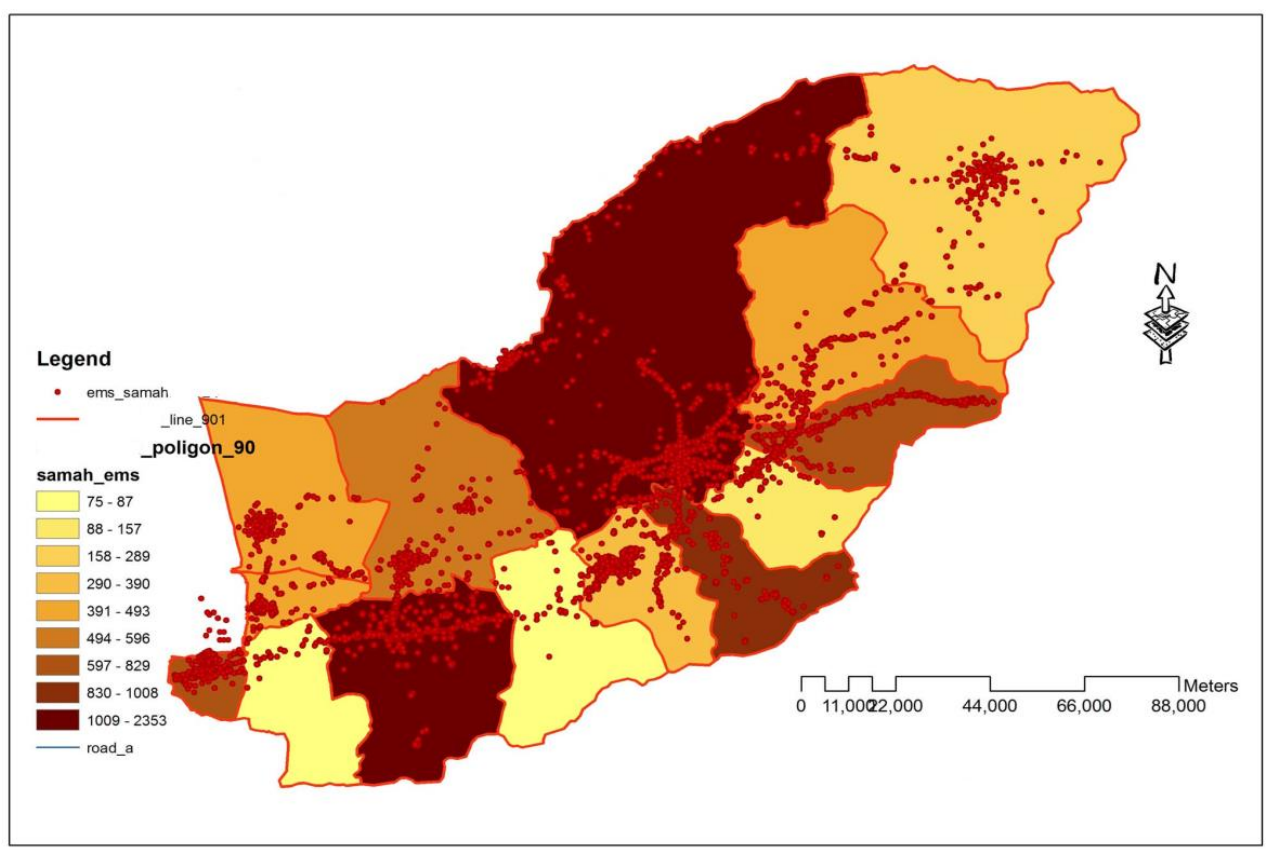

Figure 1. Distribution of RTAs in the Golestan Province during 2009-2012

The longest distance from the accident site to the nearest city was related to MaravehTappeh County $(57 \mathrm{~km})$ and Azadshahr County $(36.88 \mathrm{~km})$, while the shortest distance was related to the Galikesh County $(6.72 \mathrm{~km})$.

The average call to ambulance arrival time was 8.16 minutes, with median of 6 minutes and mode of 5 minutes. In addition, the minimum and maximum call to ambulance arrival time was one minute and 90 minutes, respectively. Furthermore, the mean ambulance response time was 7.13 minutes. As shown in figure 2, frequency of RTAs was lowest in winter and almost 2-fold higher than other seasons in summer. 


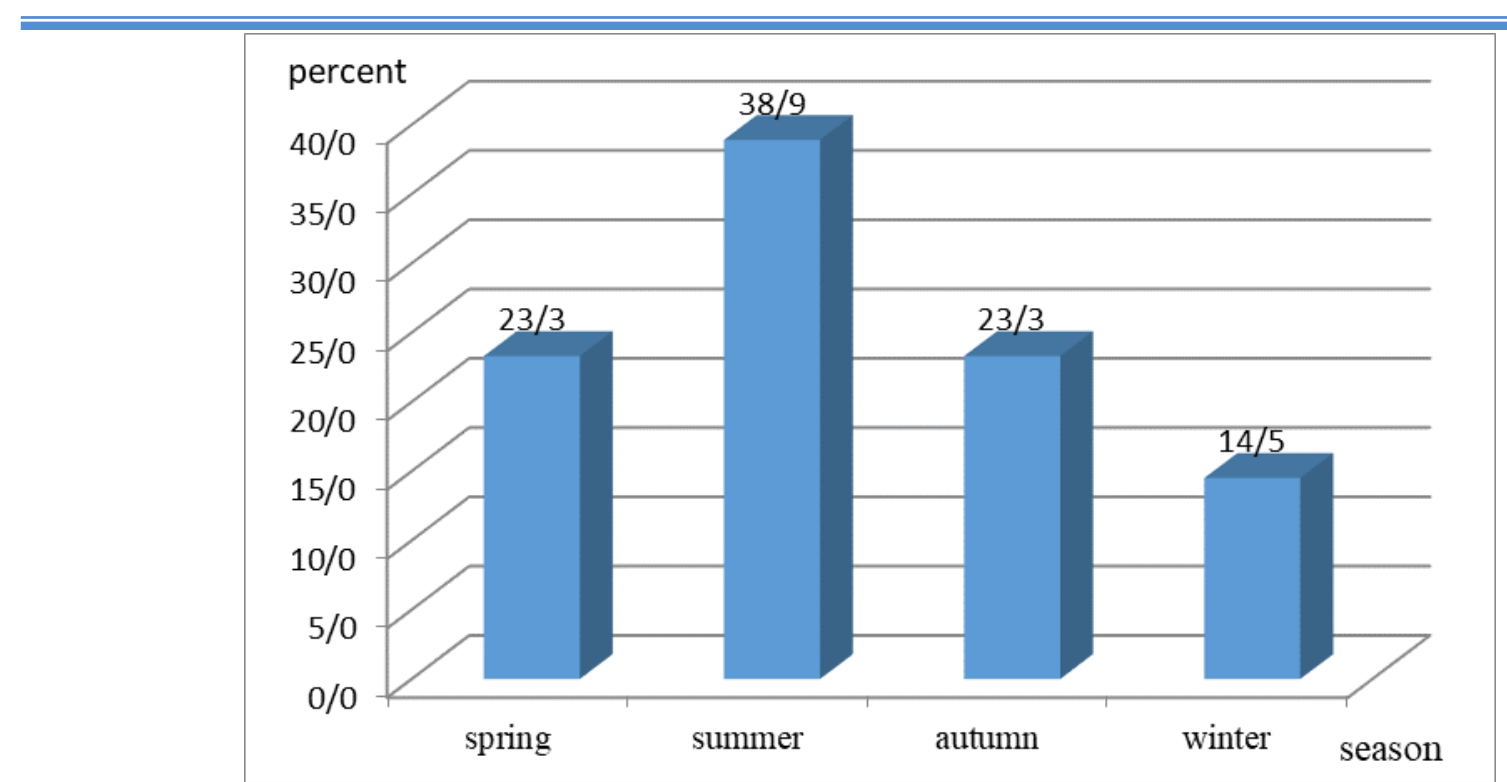

Figure 2. Seasonal distribution of RTAs in the Golestan Province during 2009-2012

The vast majority of accidents (95\%) were reported between 7 am and $12 \mathrm{pm}$, with the peak at $6 \mathrm{pm}(7.8 \%)$. In general, $76 \%$ of the accidents took place between 10 am and 9 pm.

\section{Consequences of RTAs}

In terms of consequences of RTAs, $80.7 \%$ of injured individuals were treated at hospital, and $5.9 \%$ received treatment at the accident site. Moreover, 163 individuals (1.4\%) died because of the RTAs, and mission was canceled in 1393 cases (12\%).
Demographic characteristics of injured cases

RTA-related injuries were more common among men $(82.1 \%)$ and individuals aged 2130 years $(33.5 \%)$ and $16-20$ years $(20.4 \%)$. Overall, $62.8 \%$ of RTA-related injuries affected people 16 to 35 years of age (Figure $3)$. Moreover, the mean age of injured men $(29.9 \pm 14.9$ years $)$ was significantly lower than injured women $(33.2 \pm 17$ years) $(\mathrm{P} \leq 0.001)$.



Figure 3. Frequency of injured cases in RTAs based on age group during 2009-2012 
Among the 163 mortalities caused by RTAs, 149 cases were men $(29.4 \pm 20.7$ years $)$ and 14 cases were women ( $42.1 \pm 30.4$ years).

In addition, most RTA-related deaths occurred in Gorgan (N=47), Gonbad-eKavous ( $\mathrm{N}=45)$, Kalaleh $(\mathrm{N}=14)$, Ramian
$(\mathrm{N}=13)$, and Galikesh $(\mathrm{N}=13)$ counties. The most common RTA injuries were multiple traumas (34.6\%), head and face injuries $(28.3 \%)$, and knee and leg injuries $(18.1 \%)$ (Figure 4).

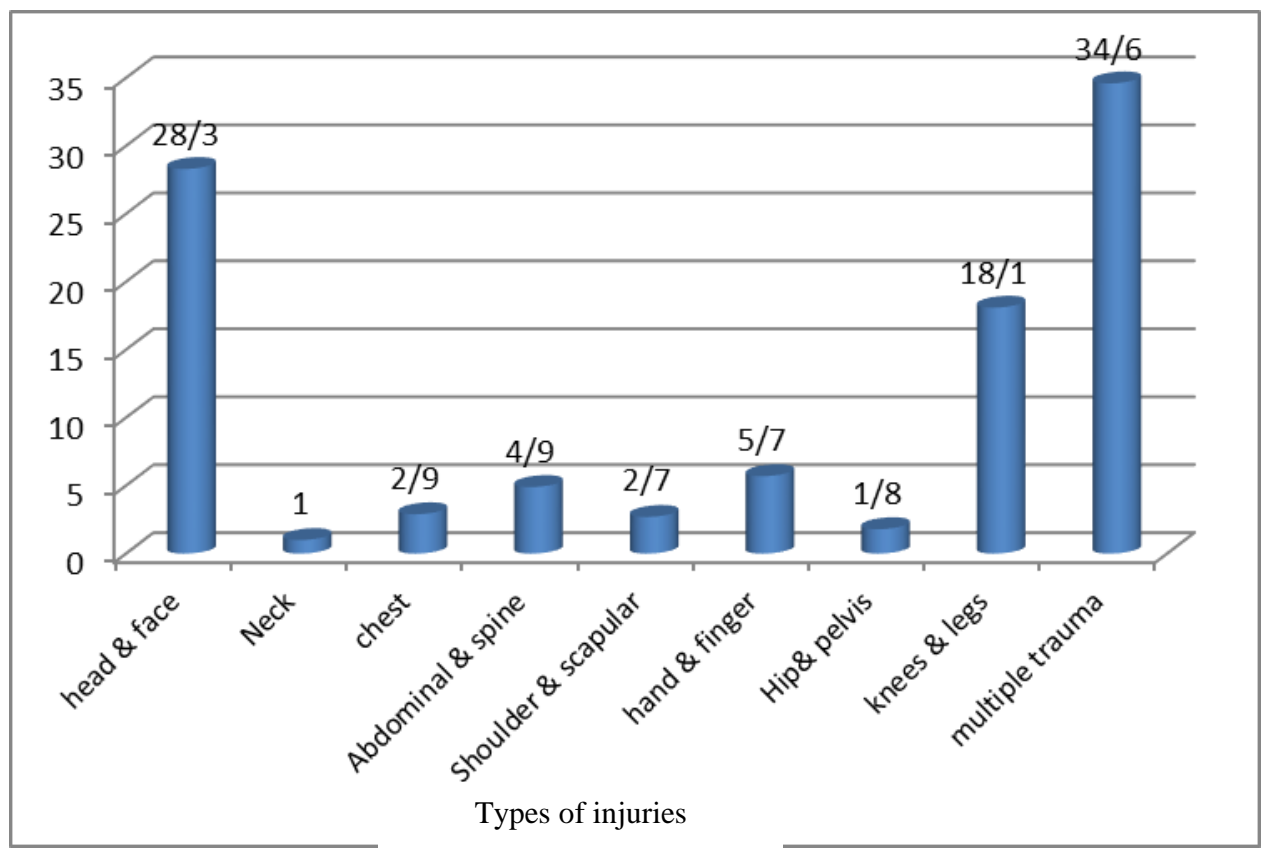

Figure 4. Percentage of RTA-related injuries in the Golestan Province by type

\section{DISCUSSION}

Similar to a study by Mohammadi in Kerman (13), we found that RTAs affected men more than women. The mean age of injured men (29.9 \pm 14.9 years) and women ( $33.2 \pm 17$ years) in our study is lower than that of a study conducted in the Guilan Province in 2012 (14). In the study area, the mortality rate was higher among men than women, which is in line with findings of several studies in Iran (7, 14-17) and other countries, such as Thailand (18) and Mexico (19). We also found that the mean age at time of death due to RTA was 30 years. According to the World Health Organization (WHO), RTAs are the primary cause of death among individuals aged 15 to 29 years, and $48 \%$ of all deaths occurs among those aged 15-44 years (20).

In our study, $80.7 \%$ of injured individuals were transferred to hospital, which is slightly lower than the rate reported in the Guilan Province $(85.9 \%)$ (14).
In line with other studies in $\operatorname{Iran}(21,22)$, we found that the frequency of RTAs in summer was almost 2-fold higher compared to other seasons. The could be due to the fact that summer is the main travel season in Iran and the Golestan Province is one of the most popular travel destinations in this season. In our study, the vast majority of accidents (95\%) were reported between 7 am and 12 $\mathrm{pm}$, with the peak at $6 \mathrm{pm}(7.8 \%)$. Another study in Iran also reported that most RTAs took place between 6 am and $8 \mathrm{pm}$ (21). This could be attributed to the relatively higher congestion levels in the evening.

In the study area, the most common RTA injuries were multiple traumas, head and face injuries, and knee and leg injuries. This findings is consistent with findings of a study in Kerman (13). Head injuries have been reported as one of the main causes of RTArelated deaths $(4,5,17)$. It seems that law 
enforcement and promoting the use of motorcycle helmets and seat belts can increase the safety of individuals and reduce the damage caused by RTAs.

Most RTAs in the Golestan Province took place in the Gonbad-e-Kavous $(23.4 \%)$ and Gorgan (21.4\%) counties, particularly at city entrance roads. This highlights the need for closer inspection of road quality/conditions and signage at these locations to prevent accidents. Considering the high rate of RTAs in the province, it is necessary to increase the number of EMS 115 sites in close proximity to accident hot spots and assign more experience personnel to these sites.

In this study, the frequency of RTAs during 2009-2012 did not differ significantly. This may indicate that no influential effort has been made by the organizations involved in accident prevention during this period.

With an average call to ambulance arrival time of 8.16 minutes and mean ambulance response time of 7.13 minutes for the mean distance of $18 \mathrm{~km}$, the EMS unit seems to be fairly prepared and responsive in the Golestan Province. According to the WHO, the most effective emergency response can be achieved through an integrated emergency dispatch or central call reception (23), which have been implemented to some extent in this province.

The strengths of the present study were its large sample size and utilization of a comprehensive software-based data system as well as a GIS software that allowed identification of accident hot spots in the province.

\section{CONCLUSION}

We demonstrated that the rate of RTAs in the Golestan Province is high, particularly at city entrance roads and in the evening and early morning. Offering training to people, especially to younger people who at higher risk of involvement in RTAs, improving road quality and signage in hot spots, and recruitment of highly-trained EMS personnel might be beneficial for reducing the number and complications of RTAs in the province.

\section{ACKNOWLEDGEMENTS}

The authors wish to thank all personnel of pre-hospital emergency sites for participating in the study.

\section{DECLARATIONS}

\section{Funding}

This study was financially supported by the Golestan University of Medical Sciences.

\section{Ethics approvals and consent to participate}

The study received approval from ethics committee of the Golestan University of Medical Sciences (code: 239791092120).

\section{Conflict of interest}

The authors declare that there is no conflict of interest.

\section{REFERENCES}

1. Organization WH. Global status report on road safety: time for action: World Health Organization; 2009.

2. Forouzanfar MH, Sepanlou SG, Shahraz S, BESc PN, Pourmalek F, Lozano R, et al. Evaluating causes of death and morbidity in Iran, global burden of diseases, injuries, and risk factors study 2010. Archives of Iranian medicine. 2014;17(5):304.

3. Rasouli MR, Nouri M, Zarei M-R, Saadat S, Rahimi-Movaghar V. Comparison of road traffic fatalities and injuries in Iran with other countries. Chinese Journal of Traumatology (English Edition). 2008;11(3):131-4. [DOI:10.1016/S10081275(08)60028-0]

4. Sadeghi-Bazargani H, Ayubi E, AzamiAghdash S, Abedi L, Zemestani A, Amanati L, et al. Epidemiological Patterns of Road Traffic Crashes During the Last Two Decades in Iran: A Review of the Literature from 1996 to 2014. Archives of trauma research. 2016;5(3):e32985. [DOI:10.5812/atr.32985]

5. Bhalla K, Naghavi M, Shahraz S, Bartels D, Murray C. Building national estimates of the 
burden of road traffic injuries in developing countries from all available data sources: Iran. Injury Prevention. 2009;15(3):150-6. [DOI:10.1136/ip.2008.020826]

6. Naghavi M, Shahraz S, Bhalla K, Jafari N, Pourmalek F, Bartels D, et al. Adverse health outcomes of road traffic injuries in Iran after rapid motorization. Arch Iran Med. 2009;12(3):284-94.

7. Modarres SR, Shokrollahi MH, Yaserian M, Rahimi M, Amani N, Manouchehri A. Epidemiological characteristics of fatal traumatic accidents in Babol, Iran: A hospital-based survey. Bulletin of emergency \& trauma. 2014;2(4):146.

8. Najimi-Varzaneh A, Fesharaki MG. Prevalence of Road Traffic Accidents in Iran: A Systematic Review, GIS and Meta-Analysis. Iranian Red Crescent Medical Journal. 2018;20(10). [DOI:10.5812/ircmj.83852]

9. Entezami N, Hashemi-Nazari SS, Soori H, Khosravi A, Ghadirzadeh MR. Epidemiology of fatal road traffic accidents in Northern provinces of Iran during 2009 to 2010. Safety Promotion and Injury Prevention. 2015;3(1):1-8 (in persian).

10. Rukewe A, Taiwo O, Fatiregun A, Afuwape O, Alonge T. GEOGRAPIC INFORMATION SYSTEMS IN DETERMINING ROAD TRAFFIC CRASH ANALYSIS IN IBADAN, NIGERIA. Journal of the West African College of Surgeons. 2014;4(3):20.

11. Charkazi A, Esmaeili A, Garkaz G, Qoreishi Z, Gerey S, Nazari S. Epidemiologic Survey of Road Traffic Accidents in Patients Admitted in Emergency Department of Alejalil Hospital in Aq-Qala City, Golestan Province. journal of health. 2012;3(2):42-9.

12. Afkhaminia F, Yazdani Charati J, Rahimi E, Mousavi Nasab N. Epidemiological Study of the Suburban Accident Mortalities Recorded in Golestan, Iran in 2015. Jorjani Biomedicine Journal. 2018;6(1):67-73. [DOI:10.29252/jorjanibiomedj.6.1.67]
13. Mohammadi G. Road traffic crash injuries and fatalities in the city of Kerman, Iran. International journal of injury control and safety promotion. 2013;20(2):184-91.

[DOI:10.1080/17457300.2012.686039]

14. Mohtasham-Amiri Z, Dastgiri S, DavoudiKiakalyeh A, Imani A, Mollarahimi K. An epidemiological study of road traffic accidents in Guilan Province, Northern Iran in 2012. Bulletin of Emergency \& Trauma. 2016;4(4):230.

15. Abbasi HR MS, Taheri Akerdi A, Niakan MH, Bolandparvaz S, Paydar S. . Pattern of Traumatic Injuries and Injury Severity Score in a Major Trauma Center in Shiraz, Southern Iran. Bull Emerg Trauma. 2013;1(2):81-5.

16. Manouchehrifar M HH, Derakhshandeh N. . Treatment Costs of Traffic Accident Casualties in a Third-level Hospital in Iran; a Preliminary Study. Emerg (Tehran). 2014;2(1):40-2.

17. Bahadorimonfared A, Soori H, Mehrabi Y, Delpisheh A, Esmaili A, Salehi M, et al. Trends of fatal road traffic injuries in Iran (2004-2011). PloS one. 2013;8(5):e65198. [DOI:10.1371/journal.pone.0065198]

18. Ditsuwan V VL, Barendregt JJ, Bertram M, Vos $\mathrm{T}$. The national burden of road traffic injuries in Thailand. Popul Health Metr. 2011;9(1):2. [DOI:10.1186/1478-7954-9-2]

19. Hijar M AA, Carrillo C, Solorzano L. Road traffic injuries in an urban area in Mexico. An epidemiological and cost analysis. Accid Anal Prev. 2004;36(1):37-42. [DOI:10.1016/S00014575(02)00112-4]

20. Organization WH. Global status report on road safety 2015: World Health Organization; 2015.

21. Khorshidi A, Ainy E, Nazari SSH, Soori H. Temporal patterns of road traffic injuries in Iran. Archives of trauma research. 2016;5(2). [DOI:10.5812/atr.27894] 
22. Sadeghi-Bazargani H, Ayubi E, AzamiAghdash S, Abedi L, Zemestani A, Amanati L, et al. Epidemiological patterns of road traffic crashes during the last two decades in Iran: a review of the literature from 1996 to 2014. Archives of trauma research. 2016;5(3). [DOI:10.5812/atr.32985]

23. Sasser S VM, Kellermann A, Lormand JD. Prehospital trauma care systems. : Geneva,World Health Organization; 2005. 